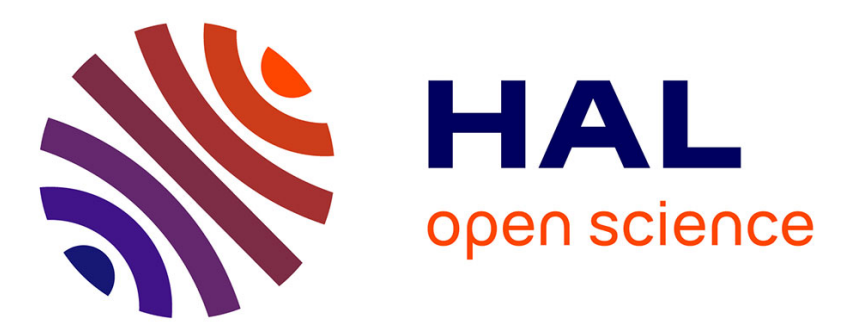

\title{
Fear of pesticide residues and preference for domestically produced strawberries
}

\author{
Anna Birgitte Milford, Nina Trandem, Armando José Garcia Pires
}

\section{To cite this version:}

Anna Birgitte Milford, Nina Trandem, Armando José Garcia Pires. Fear of pesticide residues and preference for domestically produced strawberries. Review of Agricultural, Food and Environmental Studies, 2021, 102 (4), pp.369-391. 10.1007/s41130-020-00134-8 . hal-03527986

\section{HAL Id: hal-03527986 \\ https://hal.science/hal-03527986}

Submitted on 17 Jan 2022

HAL is a multi-disciplinary open access archive for the deposit and dissemination of scientific research documents, whether they are published or not. The documents may come from teaching and research institutions in France or abroad, or from public or private research centers.
L'archive ouverte pluridisciplinaire HAL, est destinée au dépôt et à la diffusion de documents scientifiques de niveau recherche, publiés ou non, émanant des établissements d'enseignement et de recherche français ou étrangers, des laboratoires publics ou privés. 


\title{
Fear of pesticide residues and preference for domestically produced strawberries
}

\author{
Anna Birgitte Milford ${ }^{1}$ (D) - Nina Trandem ${ }^{2} \cdot$ Armando José Garcia Pires $^{3}$
}

Received: 31 July 2019 / Accepted: 17 November 2020 / Published online: 12 January 2021

(C) INRAE and Springer-Verlag France SAS, part of Springer Nature 2021

\begin{abstract}
Due to an EU directive making integrated pest management (IPM) mandatory, European farmers are expected to reduce their use of chemical pesticides, which may potentially increase production costs and risk of harvest loss. Less pesticide use is appreciated by many consumers and may generate a higher willingness to pay (WTP). However, IPM is a wide concept and it is difficult for consumers to distinguish between products with high and low risk of pesticide residues. As a result, consumers might use other characteristics, such as country of origin, for the identification of safer products. In this study, we investigate if a higher WTP for Norwegian strawberries is associated with a belief that they contain less pesticide residues than imported berries. We use regression analysis to estimate to what extent the difference in WTP for Norwegian and imported strawberries is correlated with various perceptions about strawberries. The analyses reveal that the stronger the belief that Norwegian strawberries have less pesticide risk than imported ones, the higher the WTP for Norwegian strawberries. This means that if consumers believe domestic farmers use little pesticides, domestic products might be able to sell at considerably higher prices than imports. Hence, it may be economically beneficial for farmers to keep pesticide use at a minimum. Furthermore, we find that consumers have a higher WTP for strawberries produced with less use of pesticides, although not pesticide-free, indicating that IPM is appreciated.
\end{abstract}

Keywords Strawberries · Country of origin · Pesticides · Norway · Willingness to pay (WTP) $\cdot$ Integrated pest management (IPM)

Anna Birgitte Milford

anna.birgitte.milford@nibio.no

1 Division of Food Production and Society, Norwegian Institute of Bioeconomy Research (NIBIO), Thormøhlensgate 55, 5006 Bergen, Norway

2 Division of Biotechnology and Plant Health, Norwegian Institute of Bioeconomy Research (NIBIO), P.O. Box 115, NO-1431 Ås, Norway

3 Centre for applied research at NHH (SNF), Helleveien 30, Bergen 5045, Norway 


\section{Introduction}

In 2015, Norway implemented the EU Directive 2009/128/EC on sustainable use of pesticides. An important part of this directive is to make integrated pest management (IPM) compulsory in all types of domestic agricultural production. The rationale behind the requirement to use IPM is to reduce risks posed by chemical pesticides to the environment and on producer and consumer health (Regulation (EC) 1107/2009). IPM is an agricultural practice where chemical pesticides are allowed but should be minimised and only used when strictly necessary. The directive obliges farmers to follow eight IPM principles, for example to employ preventive measures, like crop rotation, healthy plant material and protection of beneficial organisms. And to prefer non-chemical tools, such as insect traps or mechanical weed removal, to chemical ones if they give a satisfactory pest control. Farmers in Norway are required to be able to document to the Norwegian Food Safety Authority that they have followed the IPM principles whenever pesticides have been applied; for instance, they have monitored a pest insect and found its numbers sufficient to cause significant damage before applying any insecticide to control it (Barzman et al. 2015).

Because of this new legislation, agricultural producers are expected to decrease their use of chemical pesticides. This may reduce expenses on pesticides, but it may also require extra work or investments in tools or machinery. Furthermore, pesticide reduction may increase the risk of harvest loss or reduced product quality due to, for instance, insect attacks or plant diseases. The overall impact on production costs of applying less pesticides in accordance with IPM has been found to be both positive and negative (Nave et al. 2013; Rejesus 2019). But, interestingly, studies have found that reduced pesticide use may be a source for extra willingness to pay (WTP) by consumers (Brethour and Weersink 2001; Florax et al. 2005; Govindasamy and Italia 1998). An IPM price premium could potentially have compensated for additional risks of reduced yields. But obtaining this premium is problematic, as the IPM concept is complex and may be difficult to communicate to consumers, and the creation of a new labelling system may lead to information overload and market saturation of certification schemes (Lefebvre et al. 2017). Furthermore, as all agricultural producers in Norway (and the EU) are required to comply with IPM, it is not possible to charge a differentiated price in order to benefit from the extra WTP for these products (Lefebvre et al. 2015).

Does this mean that there is nothing to gain in terms of higher sale prices, for Norwegian producers who follow the IPM requirements? In this paper, we will seek to answer this question, using strawberries as a case. The basis of our study is the higher prices that Norwegian consumers are willing to pay for Norwegian strawberries. It is a fact that Norway's cold climate and high wages make agricultural production costlier than in most other countries, but that many consumers still prefer Norwegian products when buying groceries, also when they are more expensive than imported food (Kvakkestad et al. 2017; Mittenzwei et al. 2016). Thus, for a Norwegian agricultural producer, it is possible to generate a higher WTP compared with a producer from another country, simply because the product is produced in Norway. There are a range of possible explanations for this higher consumer WTP for domestic products, such as patriotism, love of your roots and origins, concern with food miles or quality expectations. In this paper, we want to investigate if a higher WTP for Norwegian strawberries to some degree is also caused by perceptions that pesticide use is lower in 
Norway than in other countries. The study thus focusses on consumers' subjective beliefs as a factor influencing WTP for a product, which in previous studies have been found to have a strong impact (Lusk et al. 2014). We hypothesise that Norwegian consumers have a higher WTP for Norwegian strawberries, partly because they believe them to be safer, in the sense that there is a lower risk of pesticide residues. If this is the case, it is in the strawberry producers' interest to keep with the IPM requirements, as this could help them maintain the reputation that they are using less harmful pesticides than countries where strawberries are imported from.

For the study, two focus group interviews and a consumer survey were conducted. Observations from the focus group discussion indicated that IPM as a concept was complicated to grasp for Norwegian consumers. To avoid confusion, the survey therefore focussed on single pesticides, corresponding with the EU directive on IPM's strong emphasize on pesticides (Regulation (EC) 1107/2009). The data generated in the survey were used in econometric regression analyses. The study identifies the positive premium for strawberries that are domestically produced and estimates which impact various beliefs about the attributes of the strawberries have on this premium. The main results are that beliefs about Norwegian strawberries having less pesticide residues, as well as general worry about pesticide residues on strawberries, are found to have a positive effect on the WTP for Norwegian strawberries when controlling for other factors.

\section{Background and literature}

\section{Strawberry production in Norway}

Approximately, $1 / 3$ of the strawberries consumed in Norway are domestically produced (OFG 2018). The main producing area is in the southeast, and the main harvesting season is from June to August. Most of the strawberry production takes place in open fields, but some producers use high plastic tunnels. This gives protection against grey mould, the most important disease in strawberries, as well as against harmful climatic conditions such as hail and heavy rainfall. Norwegian strawberry producers use different types of pesticides to protect their crops, for instance against powdery mildew, insects and mites. According to recent monitoring results for pesticide residues in food on the Norwegian market (NFST and NIBIO 2018), residues of a high number of different pesticides are often detected in strawberries. These residues are however generally below $5 \%$ of the maximum residue level for the pesticides (NFST and NIBIO 2018) and are hence regarded as not to constitute any human health risk (Regulation (EC) No 396/2005).

\section{Pesticide risk and WTP: literature review}

Pesticides are chemical or biological substances designed to control plant diseases, insect pests and weeds to ensure the quality and quantity of the crop produced. For the farmers, pesticides reduce their workload and the risk of crop loss. Different pesticides have different active ingredients with different modes of action and might target very specific or more general biological processes to control the pest in question. As a result, most pesticides contain elements that are more or less toxic to non-target organisms like 
humans, animals and beneficiary insects, and that can cause undesirable non-target effects in the environment and ecosystems. Farmers who follow regulations and instructions on pesticide use will supposedly minimise any risk to both themselves, the consumers of their product and the local environment at the production site. But many consumers are still sceptical to the use of pesticides in food production, and several studies have found that many are willing to pay more for products from a production practice with no or minimum use of chemical pesticides (Eom 1994; Florax et al. 2005; Magnusson and Cranfield 2005; Travisi et al. 2006). A reason could be that there are examples of pesticides authorised for use in crop protection that have later been banned in many countries due to post-authorization research results showing adverse health or environmental effects. The most famous example is perhaps DDT, an insecticide that was discovered to be highly persistent in the environment and that bioaccumulated in fish and birds, causing their deaths (Buckley 1986).

People's scepticism to pesticides means that many are willing to pay a higher price for food produced without the use of any synthetic pesticides, such as organically labelled food (Kvakkestad et al. 2017; Yiridoe et al. 2005). The higher the perceived environmental and health risks from pesticide exposure, the higher the WTP for pesticide reduction (Florax et al. 2005). Products with organic certificates generate a higher WTP than products produced under IPM conditions, which in turn are ranked higher than conventional products (Bazoche et al. 2014). Also, more specific information about the risks generates a higher WTP for pesticide reduction than generic (universal) information and stated preference studies exhibit higher WTP estimates compared to revealed preference studies (Travisi et al. 2006). Regarding demographic factors influencing the propensity to choose pesticide-free products, previous studies have not generated any broad consensus. There seems, however, to be a trend that females and people with higher education and with young children are more likely to buy organic products (Pearson et al. 2011), but this is not found in all studies (Magnusson and Cranfield 2005).

In an actual purchasing situation, fear of pesticide residues is just one of many different aspects that consumers will take into account when making food choices. But in their study of the relative importance of different food values, Lusk and Briggeman (2009) find that, on average, safety is the most important food value. The second most important food values are nutrition, taste and price, whereas environment, fairness and tradition are the least important food values. However, Combris et al. (2009) find in an experimental auction that preferences for the tastier alternative were stronger than preferences for safer products, or, in short, that 'taste beats food safety'.

However, although consumers might be concerned with food safety, they lack control of the production process and the ability to distinguish safe and unsafe products from each other. A study from Australia by Parker (2015) reveals that consumers have hardly any possibilities for knowing with what and how much a product has been sprayed, and even if they had, it is hard for them to assess what the health or environmental consequences could be. Because of these difficulties, consumers may use other methods to eliminate risk. Labels such as organic is one alternative. Also, the production origin can be used as a cue hinting at other characteristics of the food (Stefani et al. 2006). The country of origin is often used to stereotype information and simplify the process when consumers evaluate a product (Ahmed et al. 2004; Maheswaran 1994). As such, country of origin can be regarded as an extrinsic cue to quality (Thøgersen et al. 2017). Hence, it 
may generate a higher WTP for other reasons than for the origin itself, such as the products' sensory characteristics (as taste), and/or food safety aspects (Nygard and Storstad 1998). Loureiro and Umberger (2007) found that consumers were willing to pay a higher premium for food safety than for a country of origin label, which indicates that origin only generates a higher WTP if it is associated with other attributes such as higher food safety or quality. The authors believe that for American consumers, a country of origin label, such as 'US certified' might generate a higher premium, but when consumers are presented with additional information related to food safety, as they were in that study, the country of origin garners much smaller premiums. This is in line with other studies finding that country of origin is usually ranked among the less relevant factors to the buying decision (Moser et al. 2011). Likewise, studies on consumer preferences for organic products find that they are influenced not only by food safety and environmental considerations, but also by for instance nutritive value, taste and freshness (Yiridoe et al. 2005). It has also been found that people who tend to purchase food with credence-based attributes, such as local, organic or IPM, are often motivated by the expectation of better quality (flavour, texture), although health and sustainability are also important factors (Moser et al. 2011).

Several studies have found that consumers very often have a 'domestic country bias', which means that they have a higher willingness-to-pay for domestic than for imported products (Thøgersen et al. 2017). For instance, a study on Norwegian consumers' willingness to pay for beef found that the WTP was always higher for domestically produced beef, and always lower for beef from animals treated with hormones (Alfnes and Rickertsen 2003). An explanation for this could be that some consumers feel that it adds value in itself that a product has been domestically produced, and that purchasing imported goods is unpatriotic behaviour which can hurt their country's economy and put people out of work (Shimp and Sharma 1987).

What we can derive from this is the following: when consumers purchase a product like strawberries, they are purchasing a package of different attributes, but they do not know anything about these attributes other than what the strawberries look like. They do not know how they taste, or what happened during the production process, and if there is a risk that they will contain pesticide residues that can be harmful. So, consumers use the information they have, which in this case is the country of origin. It is known that many consumers prefer domestic products to imported ones and are willing to pay a premium for these products (Kvakkestad et al. 2017; Mittenzwei et al. 2016). We can assume that a domestically produced product carries with it certain expectations regarding for instance how it will taste and the health risks of consuming it, and these expectations depend on the beliefs the consumers hold about the product, which in turn depend on the reputation of the sector which produces it. What is also known is that consumers are willing to pay a premium for products with less pesticide risk (Florax et al. 2005), but it is difficult for them to obtain information about pesticide use in different products (Parker 2015). In this study, we want to investigate if 'produced in Norway' is used by some consumers as an extrinsic cue to identify strawberries they believe have less risk of pesticide residues, and if this partly explains the higher willingness to pay for Norwegian strawberries. This information is important, for instance, for Norwegian strawberry producers, who are in constant competition with imports, and who need to make strategic choices regarding cultivation and marketing methods (Pettersen et al. 2014). 


\section{Description of data and methodology}

\section{Data collection}

For this study, we first performed two focus group interviews in the city of Oslo, with consumers from the area, covering different age groups. The aim of the focus groups was to get insight into consumer perceptions on pesticide use in Norway, with special attention to apples and strawberries. There were 7 people in the group with people aged 18-35 and 8 in the group with people aged 36-70. The group members were recruited through a professional market research company (Norstat), and they were each paid 500 NOK (approx. 50 euros) to participate. The focus group interviews took place in November 2015, and were recorded, filmed and later transcribed. The participants signed agreements to participate in the research project, and their identities were kept anonymous. During the interviews, the participants were encouraged to share their thoughts about important factors when choosing apples and strawberries, and about the importance of pesticides, and in particular, if less pesticide use would increase their WTP. After a first discussion, the participants were given a 15 min presentation about IPM, by one of the authors who is a biologist and whose field of expertise is IPM in fruit production. Afterwards, the participants were asked if this presentation had changed their perceptions in any way. While some of the participants expressed that they had gained new and valuable knowledge, others claimed that they still did not know enough about the issue to be able to say whether they were willing to pay more for IPM-produced products. The same lack of understanding of the IPM concept was also found in a study by Anderson et al. (1996). Thus, a survey with the aim of quantifying WTP for IPM products in Norway could lead to distorted results, and we therefore decided to focus more concretely on pesticide application as a proxy for IPM. This is in line with the EU directive, which has a large emphasis on pesticides (Regulation (EC) 1107/2009).

Subsequently, a questionnaire was developed. ${ }^{1}$ An internet survey was then conducted by the market research company Norstat in November 2017. Norstat operates with internet panels with people who are paid a small amount for each survey they complete. The first question asked was how often the respondents bought strawberries in the summer and in the winter season. Respondents who rarely or never bought strawberries could not continue the survey. The final data set consisted of responses from 1004 consumers and the market research company made sure they were representing as much as possible the average Norwegian population in terms of where they live, age and gender.

The questionnaire contained questions that can be classified into five different types: (i) Stated WTP for strawberries, (ii) preferences regarding strawberries and pesticides, (iii) beliefs regarding strawberries and pesticides, (iv) reasons for preferring less pesticides and (v) demographics.

\section{WTP measures}

The respondents were initially asked to imagine that they were at the store with the aim of buying strawberries, and that a box of Belgian strawberries costed $30 \mathrm{NOK}$. Belgium is a country which exports a substantial amount of strawberries to Norway. They were

\footnotetext{
${ }^{1}$ The questionnaire was tested on 10 people who gave feedback. 
then asked if they were willing to buy an identical box of Norwegian strawberries if the price was just slightly higher, 35 NOK. If they answered 'yes', they were asked next if they were willing to pay $40 \mathrm{NOK}$ for the Norwegian strawberries, and so on until 'more than 65 NOK'. See Appendix Table 5 for full translation of question. The price examples were based on actual prices of imported and Norwegian strawberries in the summer season of 2017, provided by one of the largest supermarket chains in Norway, NorgesGruppen. According to their numbers, the average summer season price of a 500g box of imported strawberries was 30 NOK (approx. 3 Euros). The average Norwegian price was $41 \mathrm{NOK}$, although early in the summer season it could be as high as $60 \mathrm{NOK}$.

A similar question was asked about WTP for strawberries that had been produced without the pesticide pymetrozine, which in 2017 was allowed in Belgium but not in Norway, versus strawberries that had been sprayed with pymetrozine (in 2018, the EU withdrew the approval for pymetrozine). Along with this question, there was a description of the potential negative effects of this pesticide, copied from the chemistry database PubChem of the National Institutes of Health (PubChem 2017). ${ }^{2}$ As in the question about country of origin, the respondents were asked to imagine that they were at the store purchasing strawberries, and that they had the choice between a box of strawberries sprayed with pymetrozine, costing $30 \mathrm{NOK}$, and another box which had not been sprayed with pymetrozine. If they answered that they would purchase the unsprayed strawberries if they costed $35 \mathrm{NOK}$, they were given the next questions, and so on with a higher price for each question, until 65 NOK. For 150 respondents, the question about pymetrozine was asked before the question about WTP for Norwegian strawberries, to test if this had any effect. There was also a similar question about WTP for strawberries sprayed once with pyrethroid pesticides, versus five times, also with a description of this group of substances, based on information given on labels for pyrethroid pesticides in Norway. ${ }^{3}$ The intention with the question was to illustrate, without mentioning IPM as a concept, an example of a product produced with IPM, in the sense that it has been sprayed with pesticides but sparingly. For the two last WTP questions, the country of origin was not mentioned, and we used the same price intervals as for the WTP question about Norwegian strawberries.

A limit to this survey method for measuring WTP is that the answers will only be hypothetical, and we cannot tell what consumers would be willing to pay if they were actually in the described shopping situations (Travisi et al. 2006). However, the scenario with the Belgian and Norwegian strawberry baskets are quite realistic, since this is a choice situation that consumers will often find themselves in during the summer months, and with prices similar to the ones used in the survey. Hence, it is possible that the respondents are thinking back on what they actually have done in such situations, which could make the answers more credible.

\footnotetext{
2 The text reads as follows: "The pesticide «pymetrozine» is used against aphids in strawberry production in countries in the EU, including Belgium. The substance is not permitted in Norway. Pymetrozine is harmful if inhaled and suspected of causing cancer. It is also harmful to aquatic life with long lasting effects."

3 “«Pyrethroids» are pesticides used in strawberry production in Norway against pests (insects). Pyrethroids are harmful when directly swallowed or inhaled. They are very toxic to aquatic life with long lasting effects. In addition, they are toxic to bees and other insects, not only those who cause damage to the strawberries. According to Norwegian regulations it is not allowed to spray with pyrethroids 4 weeks or less before harvesting."
} 
According to Lusk et al. (2014), consumer choices are based not only on the desire to obtain the outcome provided by the product in question, but also on beliefs that the product will actually deliver this outcome. They find that in studies estimating the WTP for food safety, the consumers' beliefs about the products have a large influence. In our analysis, it is the beliefs or perceptions about Norwegian compared to imported strawberries which are at the core. The respondents were asked questions about different qualities that one typically attributes to strawberries, and their perceptions about these qualities concerning differences between Norwegian and imported strawberries, including perceptions about pesticide use. The questions were formulated as statements, which the respondents expressed to what extent they agreed with. In addition to this, the survey contained questions about preferences regarding Norwegian products and durability, reasons for being sceptical to pesticides, and beliefs about pesticides. The survey also had information about demographic background variables such as age, education, children and population density at the place of residence. For a more thorough description of the variables, see Appendix Table 5.

Taste is an attribute of Norwegian strawberries that is particularly important. Most of the strawberries imported to Norway come from Belgium, the Netherlands, Spain and Poland (SSB 2018), which generally have a longer harvesting season than in Norway. Norwegian strawberries have a reputation of being of higher quality than imported berries, and this has several explanations. One is that Norway, in comparison with most other countries, has more hours of daylight and cooler temperatures in the summer months, which generates more sugar production and thereby a sweeter taste (Davik et al. 2006). Another is that imported berries are of varieties bred to last long and be transported over large distances, and not primarily for taste qualities, while varieties which are popular in Norway, such as 'Korona', have a short durability, but a sweet taste. Furthermore, as they are closer to the market, Norwegian strawberries are harvested closer to the ripening stage, when taste qualities are more developed. It is therefore particularly important to control for the impact of the perceived taste qualities of Norwegian strawberries compared with import.

Table 1 gives an overview of the different categories of the question. The order of the questions was the same for all the respondents, except for the 150 who got the pymetrozine question before the question about WTP for Norwegian strawberries.

We perform two ordinary least square (OLS) regression analyses where we estimate the correlation between the agreement to various statements and the WTP for Norwegian strawberries. To control for heteroscedasticity, we made the estimation with robust standard errors.

Table 1 Survey design — question categories and order

2

3

4

5

6

7
WTP for Norwegian versus Belgian strawberries

Beliefs about Norwegian strawberries versus imported

Reasons for preferring less pesticides

WTP for strawberries not sprayed with the pesticide pymetrozine WTP for strawberries sprayed with less pyrethroids

Beliefs about pesticides

Demographic questions 


\section{Results}

This section presents the results of the data analysis. The descriptive statistics are presented first, followed by the presentation of the results of a regression analysis estimating the impact of different factors on WTP for Norwegian strawberries. The 'Perceptions on pesticide residues' section presents the results regarding reasons consumers worry about pesticides, and regression results estimating the impact of these worries on WTP for Norwegian strawberries, for strawberries sprayed with less pyrethroids and with no pymetrozine.

\section{Factors influencing WTP for Norwegian strawberries}

An overview of the different variables can be seen in Appendix Table 5. Table 2 shows the summary statistics for the variables used in the regression analysis, as well as for the WTP for strawberries with less pyrethroids and with no pymetrozine. All the beliefs and preference questions are ranged from 1-totally disagree to 5-totally agree.

The summary statistics show that the extra WTP for Norwegian strawberries is on average 13.4 NOK or $45 \%$ more than for the Belgian ones, which in the example costed 30 NOK. The histogram in Fig. 1 also shows the percentage distribution of the WTPs. To estimate this and the other average WTPs, we have given a WTP value of 70 NOK

Table 2 Summary statistics of variables used in the regression analysis $(N=1004)$

\begin{tabular}{|c|c|c|c|c|c|}
\hline Category & Variable & Mean & St. Dev. & Min & Max \\
\hline \multirow[t]{3}{*}{ Stated WTP } & WTP Norwegian & 43.3 & 9.5 & 30 & 70 \\
\hline & WTP less pyrethroids & 42.6 & 10.8 & 30 & 70 \\
\hline & WTP no pymetrozine & 45.5 & 10.4 & 30 & 70 \\
\hline \multirow[t]{8}{*}{ Beliefs } & Not buy at all rather than Belgian if price high & 0.6 & 0.5 & 0 & 1 \\
\hline & Norwegian strawberries better taste & 4.5 & 0.8 & 1 & 5 \\
\hline & Norwegian strawberries more nutritious & 3.5 & 0.9 & 1 & 5 \\
\hline & Less pesticides on Norwegian strawberries & 3.8 & 0.9 & 1 & 5 \\
\hline & Work conditions better for Norwegian strawberries & 3.5 & 0.8 & 1 & 5 \\
\hline & Less pollution on Norwegian strawberries & 3.4 & 0.8 & 1 & 5 \\
\hline & Norwegian strawberries longer durability & 3.0 & 0.9 & 1 & 5 \\
\hline & Government control imports of strawberries & 3.6 & 0.9 & 1 & 5 \\
\hline \multirow[t]{2}{*}{ Preferences } & Durability is important to me & 3.8 & 1.0 & 1 & 5 \\
\hline & Important to buy Norwegian to support agriculture & 4.3 & 0.8 & 1 & 5 \\
\hline \multirow[t]{8}{*}{ Demographics } & Have children under 18 in the household & 0.3 & 0.5 & 0 & 1 \\
\hline & Gender & 0.5 & 0.5 & 0 & 1 \\
\hline & Higher education & 0.2 & 0.4 & 0 & 1 \\
\hline & Age & 48.5 & 17.6 & 18 & 87 \\
\hline & Urban/rural & 2.9 & 1.2 & 1 & 5 \\
\hline & Pymetrozine question first & 1.2 & 0.4 & 0 & 1 \\
\hline & Frequency purchasing summer & 2.9 & 0.8 & 1 & 4 \\
\hline & Frequency purchasing winter & 1.6 & 0.6 & 1 & 4 \\
\hline
\end{tabular}


for those who said they were willing to pay more than 65 NOK. We have also assumed that if the respondents answer 'No' to the question if they are willing to pay $35 \mathrm{NOK}$ for Norwegian strawberries, their WTP is $30 \mathrm{NOK}$, and $35 \mathrm{NOK}$ if they say they are not willing to pay $40 \mathrm{NOK}$ and so on. We are aware that their WTP could also be any number between 30 and 35 or between 35 and 40 NOK etc., which means that the average WTP could potentially be higher. We chose to use this lower level because this is the value we know the respondents are willing to pay or claim to be so. In addition, we do not know how much more they are possibly willing to pay. Only $6 \%$ of the respondents were unwilling to pay $5 \mathrm{NOK}$ or more for the Norwegian strawberries.

Furthermore, $57 \%$ of the respondents said that if the price difference was too large, they would rather not buy any strawberries at all instead of buying the imported ones. Note that this variable was not included in the regression analysis, as this did not add any additional insight.

The WTP for the strawberries sprayed once with pyrethroids is 12.6 NOK (42\%) higher than for strawberries sprayed five times with pyrethroids. This indicates that minimising pesticide use, while not eliminating it completely, as done with IPM, generates a higher WTP among consumers. The highest WTP is generated for strawberries produced without pymetrozine: it is 52\% higher compared with those not sprayed with this pesticide.

Figure 2 gives an overview of the spread of the answers to the beliefs and preference questions.

A large proportion of the respondents, $89 \%$, agree that Norwegian strawberries taste better than imported ones, and only $3 \%$ disagree (Fig. 2). There is also a strong conviction that Norwegian strawberries are produced with less pesticides than imported ones, but a rather large share (33\%) answer 'neither nor', which means they are more uncertain. There are also more 'neither nor' answers to the other questions, but still a majority agree that Norwegian strawberries are more nutritious, and that there are better working conditions and less pollution in Norwegian strawberry production. However, a small majority (24\%) disagrees that Norwegian strawberries have a longer durability than imported ones. The figure also shows that a majority $(87 \%)$ agrees to the statement that it is important to buy Norwegian products to support Norwegian agriculture. We

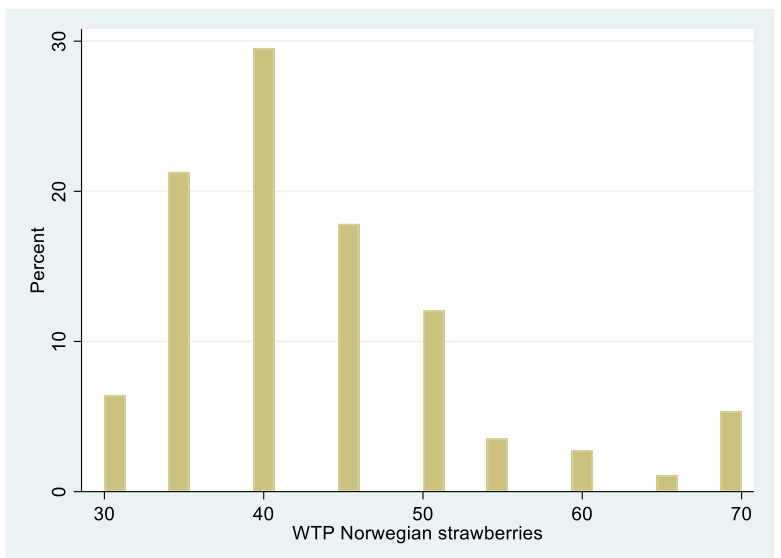

Fig. 1 Percentage distribution of WTPs for Norwegian strawberries 


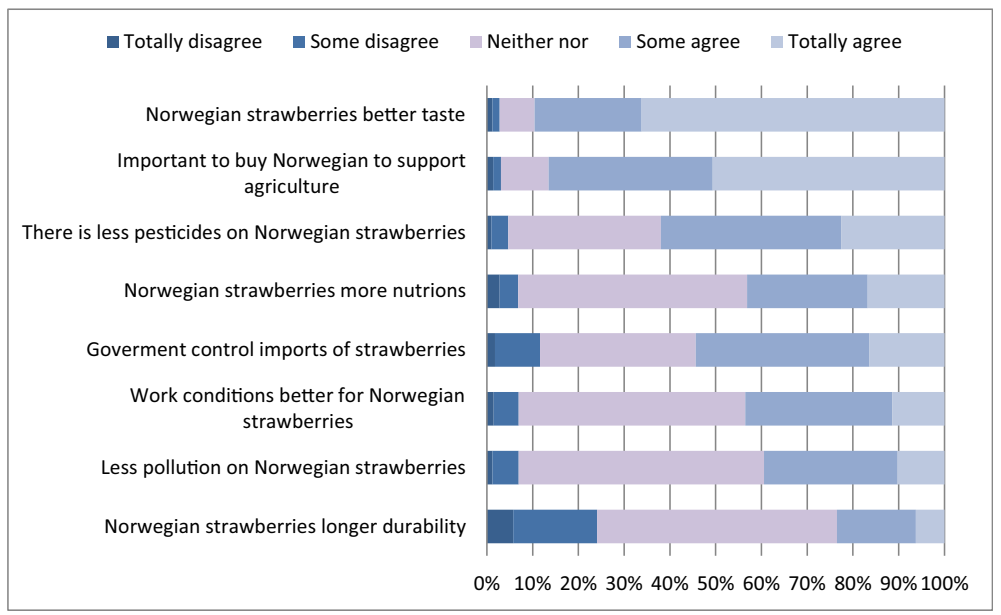

Fig. 2 Perceptions about strawberries in Norway

also see that the majority believes that the government controls that imported strawberries are safe to eat, with $54 \%$ agreeing and $12 \%$ disagreeing.

We use the variables from Table 2 (except the question about not wanting to buy any strawberries at all when prices of Norwegian strawberries get too high) to run an OLS regression analysis with the software STATA. The dependent variable is the WTP for Norwegian strawberries. We assume that the WTP is driven by the respondents' perceived utility from choosing Norwegian rather than Belgian strawberries, and that the larger this perceived utility, the larger the WTP. ${ }^{4}$

The results of the OLS regression analysis are presented in Table 3.

The analyses show that the factor most strongly correlated with WTP is the belief that Norwegian strawberries have a better taste than imported ones, with a coefficient corresponding to almost $2 \mathrm{NOK}$, and significant at the $1 \%$ level. However, we also see that the firmer the belief that the risk of pesticide residues is lower with Norwegian strawberries, the higher the WTP. The coefficient is 1.19 and it is statistically significant at the 5\% level. The same effect is not found on beliefs about local pollution and working conditions in Norway versus other countries. Believing more firmly that Norwegian authorities are able to control pesticide residues in all imports decreases the WTP, indicating that a firmer belief that imported strawberries are safe to eat, gives a lower WTP for Norwegian strawberries. We also observe that asking the question about the pesticide pymetrozine, permitted in Belgium and not in Norway, before the question about WTP for Norwegian strawberries, increases the WTP for Norwegian strawberries by $2 \mathrm{NOK}$, or $6 \%$. It seems to be the case that when altering the order of the questions, the respondents receive information about a potentially dangerous pesticide used on imported strawberries, and this influences their WTP for Norwegian strawberries. These findings show that fear of pesticide residues is a driver for WTP for Norwegian strawberries.

\footnotetext{
${ }^{4}$ Because the alternatives for WTP stopped at 'more than 65 kroner', we also perform a Tobit analysis right censoring at $>65$ to check for the robustness of the OLS regression results. The results are shown in Appendix Table 6. There are no significant differences in the results obtained.
} 
Table 3 Regression results, dependent variable WTP for Norwegian strawberries

\begin{tabular}{llcl}
\hline & Variable name & Coefficient & Std. dev. \\
\hline Beliefs & Norwegian strawberries better taste & $1.82^{* * *}$ & 0.38 \\
& Norwegian strawberries more nutritious & 0.50 & 0.39 \\
& Less pesticides on Norwegian strawberries & $1.19^{* *}$ & 0.41 \\
& Work conditions better for Norwegian strawberries & 0.49 & 0.45 \\
& Less pollution from Norwegian strawberry production & -0.33 & 0.46 \\
& Norwegian strawberries longer durability & -0.01 & 0.37 \\
& Government control imports of strawberries & $-0.93^{* *}$ & 0.33 \\
Preferences & Durability is important to me & $-1.23^{* * *}$ & 0.32 \\
& Important to buy Norwegian to support agriculture & $1.36^{* *}$ & 0.44 \\
& Have children under 18 in the household & -0.89 & 0.65 \\
& Female & -0.50 & 0.57 \\
& Higher education & 0.82 & 0.63 \\
& Age & $0.45^{* * *}$ & 0.09 \\
& Age & $-0.004^{* * *}$ & 0.00 \\
& Urban/rural & $0.79^{* *}$ & 0.24 \\
& Frequency purchasing summer & $1.99^{* * *}$ & 0.42 \\
& Frequency purchasing winter & $-1.40^{* *}$ & 0.48 \\
& Pymetrozine question first & $2.09^{*}$ & 0.91 \\
Constant & $15.01^{* * *}$ & 3.32 \\
$N$ & 1004 & \\
\hline$R^{2}$ & 0.21 & \\
\hline
\end{tabular}

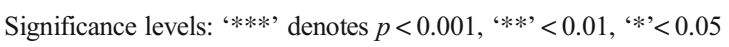

Furthermore, we see that the WTP is lower for those who claim that durability is important for them when it comes to strawberries. This reflects that Belgian or imported strawberries in general are perceived as less perishable than Norwegian ones, and those who value durability are therefore less willing to pay a higher price for Norwegian strawberries.

WTP increases with the degree of agreement to the statement about the importance of supporting Norwegian agriculture, and rural respondents have a higher WTP than urban. This indicates that paying more for Norwegian products could for some be a patriotic action taken in support of Norwegian farmers. While the age is positively correlated to WTP, i.e. older people are willing to pay more than younger, the positive age ${ }^{2}$ indicates that WTP declines over time (WTP is increasing at a decreasing rate). The point of inflexion is at the age of 56; age increases above this is correlated with a lower WTP. Gender does not influence the WTP for Norwegian strawberries, neither does education nor having children. This is in line with the findings of Magnusson and Cranfield (2005).

We also see that the WTP is higher the more frequently the respondents purchase strawberries in summer and lower the more frequently they purchase in winter. This is logical as in the winter, no Norwegian strawberries are available, and this indicates that people who purchase strawberries frequently in the winter do not mind eating imported strawberries, and hence they do not have a high additional WTP for Norwegian strawberries. 


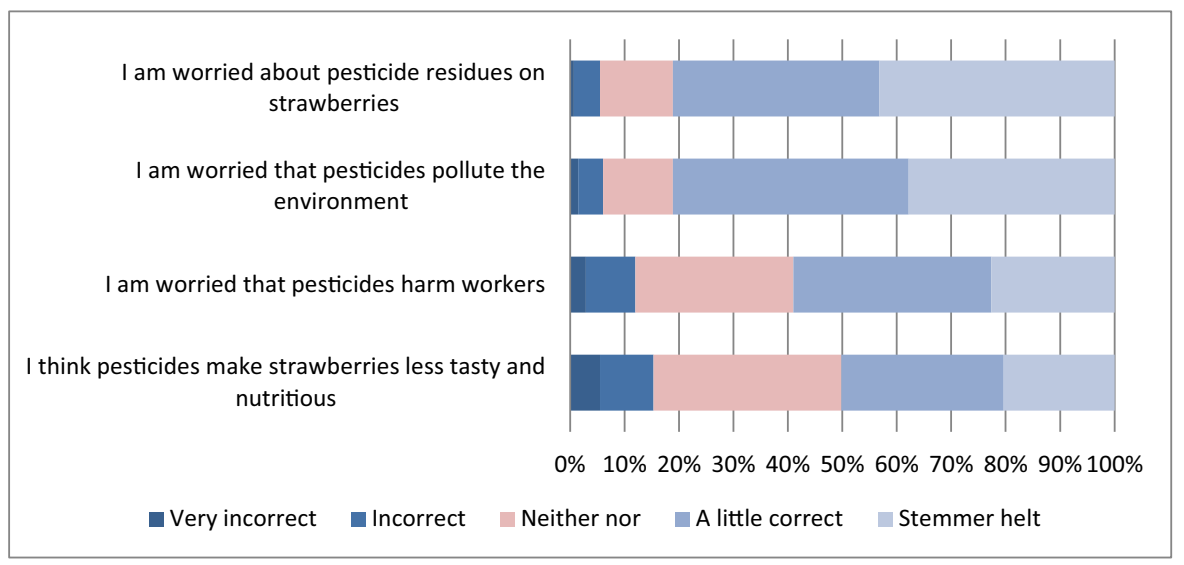

Fig. 3 Reasons for preferring less pesticides

\section{Perceptions on pesticide residues}

In the study, we also look more directly at the reasons for being worried about pesticides. The majority $(87 \%)$ of the respondents either fully or partly agreed to the statement 'I prefer that as little pesticides as possible are used on strawberries', and only $0.4 \%$ said they fully disagreed. Those who fully or partly agreed to the statement were then presented with different possible reasons for preferring low use of pesticides and asked to state to what extent these were correct.

As can be seen in Fig. 3, the most important reason for not wanting pesticides is the worry about pesticide residues on strawberries. But worries about pollution from pesticides in the environment are almost as important. A majority of the respondents also believe that pesticides harm workers or make the strawberries less tasty and nutritious, but there are far more diverse opinions about this than the two first statements. In the WTP regression analysis, only the belief that risks of pesticide residues are lower in Norway is a predictor for higher WTP for Norwegian strawberries, not perceptions about pollution from pesticides. But the answers to the question about reasons for preferring little pesticides show that the respondents are far from indifferent to the pollution of the environment from pesticides, and that they also worry about pesticides harming workers and making strawberries less tasty and nutritious.

We next perform an OLS regression analysis in order to see if the respondents' valuation of the different reasons for being worried about pesticides has any impact on their WTP for the different types of strawberries. These variables are different from the ones we have previously used, because they are not measuring beliefs about the attributes of Norwegian and imported strawberries, but the extent to which the respondents are worried about the various possible negative impacts of pesticides. It is therefore relevant to perform the analysis not only on WTP for Norwegian strawberries, but also for strawberries sprayed with less pyrethroids and with no pymetrozine. In addition to the variables for reasons for being worried about pesticides, we add the demographic variables used in the previous regression analysis. The results can be seen in Table 4 below. The number of observations (871) is lower than in the previous regression since those who did not confirm that they preferred as little pesticides as 
possible on strawberries were not asked the questions about why they worried about pesticides, and were therefore not included in the analysis.

The results show that the more worried the respondents are about pesticide residues on strawberries, the higher is their willingness to pay for Norwegian strawberries, for strawberries sprayed with less pyrethroids and for strawberries sprayed with no pymetrozine. The effect is strongest on WTP for strawberries sprayed with no

Table 4 Regression results impact of different reasons for being worried about pesticides, on WTP for Norwegian strawberries, strawberries sprayed with less pyrethroids and with no pymetrozine $(N=871)$

\begin{tabular}{|c|c|c|c|}
\hline & $\begin{array}{l}\text { WTP Norwegian } \\
\text { strawberries } \\
\text { b/se }\end{array}$ & $\begin{array}{l}\text { WTP less } \\
\text { pyrethroids } \\
\text { b/se }\end{array}$ & $\begin{array}{l}\text { WTP no } \\
\text { pymetrozine } \\
\text { b/se }\end{array}$ \\
\hline Worried pesticide residues & $\begin{array}{l}1.10^{* * *} \\
(0.39)\end{array}$ & $\begin{array}{l}1.25^{* *} \\
(0.42)\end{array}$ & $\begin{array}{l}1.51^{* * * *} \\
(0.45)\end{array}$ \\
\hline Worried pesticide pollution & $\begin{array}{c}0.80 \\
(0.44)\end{array}$ & $\begin{array}{c}0.62 \\
(0.49)\end{array}$ & $\begin{array}{l}1.02 * \\
(0.49)\end{array}$ \\
\hline Worried pesticide damage producers & $\begin{array}{r}-0.50 \\
(0.39)\end{array}$ & $\begin{array}{r}-0.28 \\
(0.46)\end{array}$ & $\begin{array}{c}0.23 \\
(0.46)\end{array}$ \\
\hline Worried pesticide affect quality & $\begin{array}{l}0.87 * * \\
(0.33)\end{array}$ & $\begin{array}{c}0.55 \\
(0.40)\end{array}$ & $\begin{array}{l}0.83^{*} \\
(0.39)\end{array}$ \\
\hline $\begin{array}{l}\text { Have children under } 18 \text { in the } \\
\text { household }\end{array}$ & $\begin{array}{c}-1.94 * * \\
(0.73)\end{array}$ & $\begin{array}{r}-1.64 \\
(0.87)\end{array}$ & $\begin{array}{r}-1.54 \\
(0.81)\end{array}$ \\
\hline Female & $\begin{array}{r}-0.70 \\
(0.64)\end{array}$ & $\begin{array}{l}1.83 * \\
(0.75)\end{array}$ & $\begin{array}{c}0.30 \\
(0.71)\end{array}$ \\
\hline Higher education & $\begin{array}{c}0.35 \\
(0.73)\end{array}$ & $\begin{array}{c}0.06 \\
(0.89)\end{array}$ & $\begin{array}{c}0.10 \\
(0.83)\end{array}$ \\
\hline Age & $\begin{array}{l}0.44 * * * \\
(0.11)\end{array}$ & $\begin{array}{l}0.37^{* *} \\
(0.13)\end{array}$ & $\begin{array}{l}0.52 * * * \\
(0.12)\end{array}$ \\
\hline $\mathrm{Age}^{2}$ & $\begin{array}{c}-0.00 * * * \\
(0.00)\end{array}$ & $\begin{array}{c}-0.00 * * \\
(0.00)\end{array}$ & $\begin{array}{c}-0.01 * * * \\
(0.00)\end{array}$ \\
\hline Urban/rural & $\begin{array}{l}1.01 * * * \\
(0.25)\end{array}$ & $\begin{array}{l}0.82 * * \\
(0.30)\end{array}$ & $\begin{array}{l}0.80^{* *} \\
(0.28)\end{array}$ \\
\hline Pymetrozine question first & $\begin{array}{l}2.88^{* *} \\
(0.91)\end{array}$ & $\begin{array}{c}1.35 \\
(0.96)\end{array}$ & $\begin{array}{r}-1.55 \\
(0.97)\end{array}$ \\
\hline Frequency purchasing summer & $\begin{array}{l}2.58 * * * \\
(0.45)\end{array}$ & $\begin{array}{c}1.23 * \\
(0.56)\end{array}$ & $\begin{array}{l}1.32 * * \\
(0.50)\end{array}$ \\
\hline Frequency purchasing winter & $\begin{array}{c}-2.22^{* * *} \\
(0.53)\end{array}$ & $\begin{array}{r}-0.38 \\
(0.64)\end{array}$ & $\begin{array}{r}-1.30^{*} \\
(0.58)\end{array}$ \\
\hline Constant & $\begin{array}{l}15.93 * * * \\
(3.14)\end{array}$ & $\begin{array}{l}18.18^{* * * *} \\
(3.68)\end{array}$ & $\begin{array}{l}18.57 * * * \\
(3.47)\end{array}$ \\
\hline$R^{2}$ & 0.13 & 0.07 & 0.12 \\
\hline
\end{tabular}

Significance levels: '***' denotes $p<0.001$, '**' $<0.01$, '*' $<0.05$ 
pymetrozine with a beta coefficient of 1.51 while the equivalent coefficient for WTP for Norwegian strawberries is 1.10 . Respondents who are more worried that pesticides will make strawberries less tasty and nutritious also have a higher WTP for Norwegian strawberries and for strawberries not sprayed with pymetrozine. In addition, the more worried the respondents are that pesticides will cause pollution to the environment, the higher is their WTP for strawberries not sprayed with pymetrozine. The demographic variables' impact on WTP for strawberries sprayed with less pyrethroids and no pymetrozine are similar to their impact on WTP for Norwegian strawberries, except that female respondents are likely to have a higher WTP for strawberries sprayed with less pyrethroids. Interestingly, having children under 18 in the household has a negative impact on WTP for Norwegian strawberries, which could possibly be because this group of people are less willing to pay for higher food taste quality than other groups.

Through the survey, we also wanted to gain insight to Norwegian consumers' knowledge and beliefs about pesticides, particularly in relation to imported and Norwegian strawberries. This is relevant because answers regarding WTP and fear of pesticides should be interpreted in the light of how much Norwegian consumers actually know about pesticides, and whether their beliefs and perceptions are overly critical or positive. The respondents were presented with a series of statements and asked to answer to what extent they believed them to be true. The statements were developed in collaboration with biologists and pesticide specialists. The results are presented in Fig. 4. Pesticides are a field where there are often uncertainties, and various sources will give different information, and we did not expect the respondents to know for certain what the correct answers were. The alternative answers were therefore made with precaution, i.e. 'I think it might be correct' and so forth. For the same reasons, we did not consider the results to be valuable as indicators of how knowledgeable the consumers were, and to be used in the regression analysis as such, but rather as indicators of their beliefs, providing more details about the causes for fear of pesticides, and reasons for believing Norwegian strawberries are safer than imported ones (Fig. 4). It is important to bear in mind that these questions were asked at the end of the questionnaire, and respondents could have been influenced by the previous questions, for instance the medical information about pymetrozine and pyrethroids. Indeed, just participating in a survey about pesticides may make the respondents more worried about it than what they would have been under different circumstances (da Costa and Santos 2016).

The results manifest a certain scepticism towards pesticides. This is shown for instance by the fact that a majority $(51 \%)$ thinks most pesticides permitted in Norway are potentially carcinogenic, which, according to available information and specialists in the area, is not the case. Furthermore, $41 \%$ do not believe in the statement that 'Pesticides permitted in Norway will not have a negative influence on health or environment when used as prescribed'.

The results also show that the respondents are sceptical to pesticide use in other countries than Norway, for instance $74 \%$ believe 'there are many chemical pesticides allowed in countries we import strawberries from, which are not permitted in Norway as they are considered harmful'. Most of the respondents also believe that control tests find more pesticides on imported than on Norwegian strawberries. Looking at the actual numbers from the Norwegian Food Authorities, control tests of strawberries in 2012-2015 found more different types of pesticide residues on imported than Norwegian strawberries, but there were findings on a larger share of the Norwegian than the 




Fig. 4 Beliefs about pesticides

imported strawberries (Mattilsynet 2017). In total, there was only one finding of residues above the maximum residue level (in an imported sample). However, these controls are done through a risk-based approach, which most consumers probably do not know, and this makes it difficult to claim that the respondents' answers are either wrong or right.

At the same time, we see that only a few respondents (15\%) do not believe that the maximum residue level for pesticides is normally set 100 times lower than a human is expected to tolerate with daily intake over a lifetime, which indicates that a majority feel a certain trust in the regulatory system concerning pesticides. Furthermore, a majority believe that authorities control most foreign deliveries of strawberries to check for pesticide residues, indicating an excessive trust at this point, as in reality the authorities only control a small share of the imported berries every year.

Hence, these results indicate both a fear of pesticide residues based on beliefs not compatible with expertise knowledge (although there is possibly an influence by the previous survey questions), and a belief that authorities are controlling more than they actually do. Similar attitudes were expressed in the focus group interviews. Certain statements also revealed confusion because of the lack of knowledge about pesticides. One participant stated the following: 'I think a bit about if the fruit trees are being sprayed, but then I think, ok, but where can I check it? And then I end up not doing it. But it could be that 
it is dangerous stuff.' Another participant also expressed frustration because the question of pesticides comes on top of many other ethical and safety issues that consumers are faced with when choosing which food items to buy. In particular: 'There are thousands of products to make a decision upon during a month, and there is micro plastic and palm oil and a whole lot of crap which is not good for the environment. It is very hard to be a consumer in that situation.'

\section{Discussion and conclusion}

Our results imply that Norwegian consumers have a high WTP for Norwegian strawberries. It is important to keep in mind that the WTP derived in this study is based on the respondents' stated preferences, and not on what they are actually willing to pay while shopping, which might be different (Travisi et al. 2006). But the numbers derived do, in fact, correspond with actual numbers from Norwegian supermarkets on price differences between Norwegian and imported strawberries. The higher WTP is strongly correlated with the respondents' perceptions about the quality of Norwegian strawberries, but also beliefs about pesticide residues on Norwegian strawberries. In a second regression analysis, we also find that WTP for Norwegian strawberries is influenced by worries in general about pesticide residues. Our paper contributes to the literature that separates the premium for different attributes in a single product, similar to for instance the case of organic food that has both health, environmental, animal welfare and quality attributes (Yiridoe et al. 2005). Our finding that quality and taste is more important than food safety corresponds with the results of the study by Combris et al. (2009). Nevertheless, our results clearly show that reduced pesticide use is appreciated by consumers. This is further supported by the fact that very few respondents disagreed to the statement that they prefer as little pesticides as possible on their strawberries. We also found that asking the question about pymetrozine, a potentially carcinogenic pesticide allowed in Belgium, but not in Norway, before the question about WTP for Norwegian strawberries, increased the WTP significantly.

Our study also finds that while the WTP for Norwegian strawberries is influenced by perceived differences between Norwegian and imported strawberries concerning pesticide residues, we do not find the same correlation with perceptions about local pollution or working conditions. This is to some extent confirmed in the second regression analysis. The stronger emphasis on own risk exposure is in accordance with previous studies (Lusk and Briggeman 2009; Travisi et al. 2006). However, Fig. 3 shows that worry about environmental pollution from pesticides is almost as high as worry about pesticide residues, and in the case of WTP for strawberries not sprayed with pymetrozine, the regression results show a positive impact from worry about pollution from pesticides. Hence, we detect an impact on WTP from worry about pollution from pesticides, but not from worry about strawberry workers' exposure to pesticide risk.

It should be taken into account that answers to questions asked late in the questionnaire may have been influenced by previous questions, as proven with the changing of order of the pymetrozine question for some respondents. Having several questions about WTP for different types of products in the same survey, there is also a possibility for there being an anchoring bias, meaning that the second and third stated WTPs are influenced by the previous one. Furthermore, it is unlikely that strawberries are representative for all types of agricultural products. In the focus group interview, it was mentioned that strawberries 
have a reputation of being more frequently sprayed with pesticides than other products, and they are also perceived as riskier to eat because they are usually eaten raw, and there is no peel to remove. As explained by one of the participants: 'I think it is more dangerous to eat strawberries the way we eat them, because strawberries are so difficult to wash'. Another reason why the WTP for strawberries might be higher than for other types of Norwegian food is, as explained earlier, that Norwegian strawberries might have some quality advantages compared to imports, which other agricultural products might not have to the same extent. However, given the perceived higher quality attributes of Norwegian strawberries, it is interesting to observe that the stated WTP for strawberries sprayed without the pesticide pymetrozine, or with less use of pyrethroid pesticides, is higher or as high as for Norwegian strawberries compared with imports.

To conclude, the results of our study show that Norwegians have a higher WTP for domestically produced strawberries than for imported ones. Our study is the first to reveal that this higher WTP is associated with perceptions that Norwegian strawberries contain less pesticide residues than imported ones. We also find that the difference in WTP is almost as high for strawberries produced with less use of pesticides, although not pesticide-free, and that it is higher for strawberries produced without a possibly carcinogenic pesticide not allowed in Norway (pymetrozine). Although perceptions about Norwegian strawberries having a superior taste is found to be a more important predictor for a higher WTP, our study shows that Norwegian consumers clearly are concerned about pesticide residues in strawberries, and willing to pay a higher price for strawberries that have not been sprayed or that have been sprayed less than others.

As it is mandatory for all producers to use IPM methods, it is not possible to gain income from an extra WTP from consumers by branding products with an IPM certification label. However, the results from this study show that the Norwegian strawberries' reputation of having less pesticide residues generates extra WTP from domestic consumers. This again indicates that efforts made by Norwegian strawberry producers to keep pesticide use low are worthwhile also from an income perspective. It is also an important task for the Norwegian Food Safety Authorities to maintain the level of pesticide use at a safe level through regulations, education and control. In the eventual case of negative media attention to pesticide use among Norwegian strawberry producers, for instance caused by one producer's mistake or misuse, it could damage the reputation of the entire sector, and reduce consumer WTP for Norwegian strawberries in general.

The directive for IPM applies to all EU farmers, which could make one think that there is no difference in pesticide risk between EU countries. However, few consumers have knowledge about this directive, and that it applies to both Norway and the EU. But even if they did, pesticide regulations and to what extent farmers obey to them may still vary among countries, which means that pesticide regulations could be stricter, or producer practices more in line with IPM in one country, for instance Norway, than another. Norway, as a country outside of the EU and with citizens who have a high level of trust in other people, ${ }^{5}$ may be a distinctive case. But it is also possible that similar results to the ones from this study could have been obtained if it had been conducted in another EU country, assuming that consumers trust producers from their own country more than foreign producers. But this needs to be investigated further.

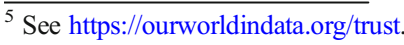


Lastly, our study implies that strict pesticide regulations and implementation of IPM on farms are valued by consumers, and therefore that, at least in the case of strawberries, policies for reduced use of pesticides are in line with aims for increased public welfare.

Acknowledgements We would like to thank Marianne Stenrød and Valborg Kvakkestad for valuable comments.

Author contributions Anna Birgitte Milford conceived the idea and designed the study, and was responsible for conducting the survey, analysing the results and writing the article. Nina Trandem contributed to development of survey and focus group questions and participated in the focus groups. Armando Pires gave advice to the econometric analysis. Nina Trandem and Armando Pires contributed to discussion of the results and to writing the manuscript.

Funding The study was funded by the Norwegian Research Council (project number 244526 and 268273).

Data availability The data from the survey can be made available from the authors on request.

\section{Compliance with ethical standards}

Conflict of interest The authors declare that they have no conflict of interest.

\section{Appendix}

Table 5 Overview variables

WTP Norwegian

WTP less pyrethroids

WTP no pymetrozine

Not buy at all rather than Belgian if price high

Norwegian strawberries better taste
Willingness to pay for box of Norwegian compared to Belgian strawberries. Question used: Imagine that you are at the store and you have decided to buy a box of strawberries. A box with $500 \mathrm{~g}$ strawberries from Belgium costs $30 \mathrm{NOK}$. Imagine that you have the possibility to buy an equivalent box of Norwegian strawberries. Do you think you would be willing to buy the Norwegian instead of the Belgian of the price of the Norwegian were $35(40,45 \ldots 65)$ $\mathrm{NOK} / \mathrm{box}$ ? (Y/N)

Willingness to pay for box of strawberries sprayed once with less pyrethroids. Question used: Imagine that you are at the store and you have decided to buy a $500 \mathrm{~g}$ box of strawberries. You have the choice between box A, sprayed 5 times with pyrethroids, costing 30 NOK and box B, sprayed once with pyrethroids. Do you think you would be willing to buy box B instead of box A if box B costed 35 NOK?

Willingness to pay for box of strawberries not sprayed with pymetrozine. Question used: Imagine that you are at the store and you have decided to buy a $500 \mathrm{~g}$ box of strawberries. You have the choice between box A, sprayed with pymetrozine, costing 30 NOK and box B, Not sprayed with pymetrozine. Do you think you would be willing to buy box B instead of box A if box B costed 35 NOK?

Answer to question: 'If the price of the Norwegian strawberries is very high, do you think you would not buy any strawberries at all, rather than buying the Belgian ones?' ( $\mathrm{Y} / \mathrm{N}$ )

Answer to question: 'To what extent do you agree that Norwegian strawberries taste better than most foreign?' 
Table 5 (continued)

Norwegian strawberries more nutritious

Less pesticides on Norwegian strawberries

Work conditions better for Norwegian strawberries

Less pollution on Norwegian strawberries

Norwegian strawberries longer durability

Durability is important to me Important to buy Norwegian to support agriculture

Government control imports of strawberries

Have children under 18 in the household

Gender

Higher education

Worried pesticide residues

Worried pesticide pollution

Worried pesticide damage producers

Worried pesticide affect quality

Age

Urban/rural

Pymetrozine question first

Frequency purchasing strawberries summer/winter
Answer to question: 'To what extent do you agree that Norwegian strawberries have more healthy nutrients than most foreign?'

Answer to question: 'To what extent do you agree that there is a higher danger of harmful pesticide residues on foreign than on Norwegian strawberries?'

Answer to question: 'To what extent do you agree that working conditions for those working with strawberries are worse in most other countries compared to Norway?'

Answer to question: 'To what extent do you agree that there is less local pollution from strawberry production in other countries compared with Norway?'

Answer to question: 'To what extent do you agree that Norwegian strawberries have longer durability after purchase than most foreign?'

Answer to the question: 'How important is durability for you?'

Answer to question: 'To what extent do you agree to the statement: 'It is important to support Norwegian agriculture by purchasing Norwegian food products'?'

Answer to question: 'To what extent do you agree to the statement:

'Norwegian authorities control that strawberries imported here are safe to eat'?'

Dummy variable based on answer to question: How many people in the household are below 18 ?

0 male, 1 female

Dummy variable, 1 have completed university/college education, 0 have not completed university/college education

Answer to question: 'Do you prefer less chemical pesticides because: I am worried about health damaging pesticide resides on strawberries"

Answer to question: 'Do you prefer less chemical pesticides because: I am worried about pesticides polluting the environment"

Answer to question: 'Do you prefer less chemical pesticides because: I am worried about strawberry producers being harmed by pesticides'

Answer to question: 'Do you prefer less chemical pesticides because: I think the pesticides make the strawberries less nutritious and tasty"

Population size at place of residence, going from 1 - high population density (Oslo) to 5-low population density (countryside, less than 2000 inhabitants)

Dummy variable, 1 received the question about WTP for strawberries not sprayed with pymetrozine before the question about WTP for Norwegian strawberries, 0 received the question about WTP for strawberries not sprayed with pymetrozine further back in questionnaire

Answer to question: 'How often do you buy strawberries in summer/ winter?' 1 rarely or never, 4 several times a week 
Table 6 Tobit regression result, dependent variable WTP for Norwegian strawberries

\begin{tabular}{lcc}
\hline Variable name & Coefficient & Std. dev. \\
\hline Norwegian strawberries better taste & $1.81^{* * * *}$ & 0.38 \\
Norwegian strawberries more nutritious & 0.46 & 0.38 \\
Less pesticides on Norwegian strawberries & $1.19^{* * *}$ & 0.41 \\
Work conditions better for Norwegian strawberries & 0.48 & 0.41 \\
Less pollution from Norwegian strawberry production & -0.33 & 0.43 \\
Norwegian strawberries longer durability & 0.01 & 0.32 \\
Durability is important to me & $-1.23^{* * *}$ & 0.29 \\
Important to buy Norwegian to support agriculture & $1.35^{* * *}$ & 0.38 \\
Government control imports of strawberries & $-0.91 * * *$ & 0.29 \\
Have children under 18 in the household & -0.85 & 0.64 \\
Gender & -0.44 & 0.55 \\
Higher education & 0.87 & 0.64 \\
Age & $0.44^{* * *}$ & 0.10 \\
Age ${ }^{2}$ & $0.004^{* * * *}$ & 0.001 \\
Urban/rural & $0.75^{* * *}$ & $1.99^{* * *}$ \\
Pymetrozine question first & $1.99^{* * *}$ & 0.23 \\
Frequency purchasing summer & $-1.36^{* *}$ & 0.75 \\
Frequency purchasing winter & $12.56^{* * * *}$ & 0.39 \\
Constant & 1004 & 0.47 \\
Pseudo $R^{2}$ & 0.03 & 3.26 \\
\hline & & \\
\hline
\end{tabular}

Significance levels: ‘***' denotes $\mathrm{p}<0.001$, '**' $<0.01$, '*' $<0.05$

\section{References}

Ahmed, Z. U., Johnson, J. P., Yang, X., Fatt, C. K., Teng, H. S., \& Boon, L. C. (2004). Does country of origin matter for low-involvement products? International Marketing Review, 21(1), 102-120. https://doi.org/ $10.1108 / 02651330410522925$.

Alfnes, F., \& Rickertsen, K. (2003). European consumers' willingness to pay for US beef in experimental auction markets. American Journal of Agricultural Economics, 85(2), 396-405. https://doi.org/10.1111/ 1467-8276.t01-1-00128.

Anderson, M. D., Hollingsworth, C. S., VanZee, V., Coli, W. M., \& Rhodes, M. (1996). Consumer response to integrated pest management and certification. Agriculture Ecosystems \& Environment, 60(2-3), 97106. https://doi.org/10.1016/S0167-8809(96)01097-3.

Barzman, M., Bàrberi, P., Birch, A. N. E., Boonekamp, P., Dachbrodt-Saaydeh, S., Graf, B., Hommel, B., Jensen, J. E., Kiss, J., Kudsk, P., Lamichhane, J. R., Messéan, A., Moonen, A.-C., Ratnadass, A., Ricci, P., Sarah, J.-L., \& Sattin, M. (2015). Eight principles of integrated pest management. Agronomy for Sustainable Development, 35, 1199-1215.

Bazoche, P., Combris, P., Giraud-Heraud, E., Pinto, A., Bunte, F., \& Tsakiridou, E. (2014). Willingness to pay for pesticide reduction in the EU: nothing but organic? European Review of Agricultural Economics, 41(1), 87-109. https://doi.org/10.1093/erae/jbt011.

Brethour, C., \& Weersink, A. (2001). An economic evaluation of the environmental benefits from pesticide reduction. Agricultural Economics, 25(2-3), 219-226.

Buckley, J. (1986). Environmental effects of DDT. In National Research Counsel (Ed.), Ecological knowledge and environmental problem-solving: concepts and case studies (pp. 358-374). Washington, D.C.: National Academies Press.

Combris, P., Pinto, A. S., Fragata, A., \& Giraud-Héraud, E. (2009). Does taste beat food safety? Evidence from the "Pêra Rocha" case in Portugal. Journal of Food Products Marketing, 16(1), 60-78. 
da Costa, C. A., \& Santos, J. L. (2016). Estimating the demand curve for sustainable use of pesticides from contingent-valuation data. Ecological Economics, 127, 121-128.

Davik, J., Bakken, A. K., Holte, K., \& Blomhoff, R. (2006). Effects of genotype and environment on total anti-oxidant capacity and the content of sugars and acids in strawberries (Fragaria X ananassa Duch.). The Journal of Horticultural Science and Biotechnology, 81(6), 1057-1063. https://doi.org/10.1080/ 14620316.2006.11512171.

Eom, Y. S. (1994). Pesticide-residue risk and food safety valuation - a random utility approach. American Journal of Agricultural Economics, 76(4), 760-771. https://doi.org/10.2307/1243737.

Florax, R. J. G. M., Travisi, C. M., \& Nijkamp, P. (2005). A meta-analysis of the willingness to pay for reductions in pesticide risk exposure. European Review of Agricultural Economics, 32(4), 441-467. https://doi.org/10.1093/erae/jbi025.

Govindasamy, R., \& Italia, J. (1998). A willingness-to-purchase comparison of integrated pest management and conventional produce. Agribusiness: An International Journal, 14(5), 403-414.

Kvakkestad, V., Berglann, H., Refsgaard, K., \& Flaten, O. (2017). Citizen and consumer evaluation of organic food and farming in Norway. Organic Agriculture, 8(2), 87-103.

Lefebvre, M., Langrell, S. R. H., \& Gomez-Y-Paloma, S. (2015). Incentives and policies for integrated pest management in Europe: a review. Agronomy for Sustainable Development, 35(1), 27-45.

Lefebvre, M., Biguzzi, C., Ginon, E., Gomez-y-Paloma, S., Langrell, S. R. H., Marette, S., et al. (2017). Mandatory integrated pest management in the European Union: experimental insights on consumers' reactions. Review of Agricultural, Food and Environmental Studies, 98, 25-54. https://doi.org/10.1007/ s41130-017-0041-x.

Loureiro, M. L., \& Umberger, W. J. (2007). A choice experiment model for beef: What US consumer responses tell US about relative preferences for food safety, country-of-origin labeling and traceability. Food Policy, 32(4), 496-514. https://doi.org/10.1016/j.foodpol.2006.11.006.

Lusk, J. L., \& Briggeman, B. C. (2009). Food Values. American Journal of Agricultural Economics, 91(1), 184-196. https://doi.org/10.1111/j.1467-8276.2008.01175.x.

Lusk, J. L., Schroeder, T. C., \& Tonsor, G. T. (2014). Distinguishing beliefs from preferences in food choice. European Review of Agricultural Economics, 41(4), 627-655.

Magnusson, E., \& Cranfield, J. A. L. (2005). Consumer demand for pesticide free food products in Canada: a probit analysis. Canadian Journal of Agricultural Economics-Revue Canadienne D Agroeconomie, 53(1), 67-81. https://doi.org/10.1111/j.1744-7976.2005.00354.x.

Maheswaran, D. (1994). Country of origin as a stereotype: effects of consumer expertise and attribute strength on product evaluations. Journal of Consumer Research, 21(2), 354-365.

Mattilsynet (2017). Rester av plantevernmidler i bær 2012-2015. Report Mattilsynet and NIBIO. https://www. mattilsynet.no/mat_og_vann/uonskede_stofferimaten/rester_av_plantevernmidler_i_mat/rester_av_ plantevernmidler_i_baer_20122015.25248-1 Accessed Jun 2017.

Mittenzwei, K., Mann, S., Refsgaard, K., \& Kvakkestad, V. (2016). Hot cognition in agricultural policy preferences in Norway? Agriculture and Human Values, 33(1), 61-71.

Moser, R., Raffaelli, R., \& Thilmany-McFadden, D. (2011). Consumer preferences for fruit and vegetables with credence-based attributes: a review. International Food and Agribusiness Management Review, 14(2), 121-142.

Nave, S., Jacquet, F., \& Jeuffroy, M. (2013). Why wheat farmers could reduce chemical inputs: evidence from social, economic, and agronomic analysis. Agronomy for Sustainable Development, 33, 795-807. https:// doi.org/10.1007/s13593-013-0144-y.

NFST (Norwegian Food Safety Authority) and NIBIO, 2018. Pesticide residues in food and feed 2017. (In Norwegian with english summary: Rester av plantevernmidler i næringsmidler 2017.) Ås, Norway. 97 pp. ISBN: 978-82-92650-02-8.

Nygard, B., \& Storstad, O. (1998). De-globalization of food markets? Consumer perceptions of safe food: the case of Norway. Sociologia Ruralis, 38(1), 35. https://doi.org/10.1111/1467-9523.00062.

OFG. (2018). Totaloversikten 2017. Report. https://www.frukt.no/presse/statistikk/ Accessed Jun 2018.

Parker, C. (2015). Strawberry fields forever: can consumers see pesticides and sustainability as an issue? Sustainability Science, 10(2), 285-303. https://doi.org/10.1007/s11625-014-0267-3.

Pearson, D., Henryks, J., \& Jones, H. (2011). Organic food: what we know (and do not know) about consumers. Renewable Agriculture and Food Systems, 26(2), 171-177.

Pettersen, I., Nebell, I., \& Prestvik, A. (2014). Grønn verdi. NILF-Report: Lønnsom vekst for norsk frukt og grønt.

PubChem (2017). U.S. National Library of Medicine. https://pubchem.ncbi.nlm.nih.gov/ Accessed Jun 2017.

\section{Springer}


Rejesus, R. (2019). What can we learn from more recent (and more 'rigorous') economic impact assessments of Integrated Pest Management Farmer Field Schools (IPM-FFS)? In D. Onstad \& P. Crain (Eds.), The economics of integrated pest management of insects (pp. 35-48). Wallingford: CABI.

Shimp, T. A., \& Sharma, S. (1987). Consumer ethnocentrism: construction and validation of the CETSCALE. Journal of Marketing Research, 24(3), 280-289.

SSB (Statistics Norway) (2018): www.ssb.no Accessed Jan 2017.

Stefani, G., Romano, D., \& Cavicchi, A. (2006). Consumer expectations, liking and willingness to pay for specialty foods: do sensory characteristics tell the whole story? Food Quality and Preference, 17(1-2), 53-62. https://doi.org/10.1016/j.foodqual.2005.07.010.

Thøgersen, J., Pedersen, S., Paternoga, M., Schwendel, E., \& Aschemann-Witzel, J. (2017). How important is country-of-origin for organic food consumers? A review of the literature and suggestions for future research. British Food Journal, 119(3), 542-557. https://doi.org/10.1108/BFJ-09-2016-0406.

Travisi, C. M., Nijkamp, P., \& Vindigni, G. (2006). Pesticide risk valuation in empirical economics: a comparative approach. Ecological Economics, 56(4), 455-474. https://doi.org/10.1016/j.ecolecon.2004. 06.026 .

Yiridoe, E. K., Bonti-Ankomah, S., \& Martin, R. C. (2005). Comparison of consumer perceptions and preference toward organic versus conventionally produced foods: a review and update of the literature. Renewable Agriculture and Food Systems, 20(4), 193-205. https://doi.org/10.1079/Raf2005113.

Publisher's note Springer Nature remains neutral with regard to jurisdictional claims in published maps and institutional affiliations. 